\title{
A história esquecida do trotskismo na Revolução Espanhola: o POUM e os "bolchevique-leninistas"
}

\author{
The forgotten history of Trotskyism in the Spanish Revolution: the POUM \\ and the "Bolshevik-Leninists"
}

\author{
Marcio Lauria Monteiro*
}

\begin{abstract}
Resumo
O presente artigo aborda a história do trotskismo na Revolução Espanhola. Ele visa esclarecer a real relação do POUM com essa corrente política -buscando desfazer a frequente e errônea associação entre ambos-e detalhar a atuação prática e as análises e elaborações políticas de Leon Trotski e de seus aliados na Espanha à época. Esse esforço de resgate histórico utiliza principalmente fontes secundárias -obras de análise histórica pouco conhecidas do público geral - e, em menor medida, algumas fontes primárias- em especial escritos de Trotski acerca do assunto).
\end{abstract}

Palavras-chave: Revolução Espanhola; Guerra Civil Espanhola; POUM; Leon Trotski; Quarta Internacional; Trotskismo.

\begin{abstract}
This article deals with the history of Trotskyism in the Spanish Revolution. It aims at clarifying the actual relationship of the POUM with this political current -by attempting to deconstruct the frequent and erroneous association of the two - and at detailing the practical activity and the political analyses of Leon Trotsky and his allies in Spain at the time. This effort of a historical rescue is based upon mainly in secondary sources works of historical analysis that are little known of the general public- and, in a smaller portion, also on some primary sources - especially Trotsky's writings on the subject.
\end{abstract}

Keywords: Spanish Revolution; Spanish Civil War; POUM; Leon Trotsky; Fourth International; Trotskyism.

Recibido: 16 agosto 2016

Aceptado: 22 noviembre 2016

\footnotetext{
* Brasileiro, Mestre em História pela Universidade Federal Fluminense e Pós-graduando em História dos Movimentos Sociais e Revoluções (especialização) pela Universidade Estadual de Maringá. Uma versão preliminar do presente artigo foi publicada no blog Junho, em 29 de julho de 2016 (disponível em http://tinyurl.com/hkzwj4t). Agradeço à Profa. Dra. Raquel Varela pela leitura atenciosa da versão original e pelas sugestões de melhorias, à Morgana Romão pela revisão e ao parecerista de Izquierdas pelas indicações bibliográficas adicionais. Ressalto que qualquer erro ou falha são de minha inteira responsabilidade. Para contato, críticas e sugestões: marciolmonteiro@gmail.com e https://uff.academia.edu/MarcioLauriaMonteiro.
} 
Para compreender a tragédia de 26 de janeiro de 1939, teremos de recordar a de 3-6 de maio de 1937. Entre essas duas datas há uma relação lógica. Quando se esmagou a revolução, esmagou-se a guerra anti-fascista

M. Casanova (Mieczyslaw Bortenstein), voluntário que combateu na Espanha entre 1936-39 e dirigente bolchevique-leninista.

Em julho de 2016 completaram-se 80 anos do começo do golpe de Estado encabeçado pelo general Francisco Franco y Bahamonde contra o governo republicano da Frente Popular (no dia 17, ainda no Marrocos) e do levante revolucionário que os trabalhadores do Estado Espanhol realizaram em resposta ao mesmo (a partir do dia 19). Nessas oito décadas, muito já se escreveu sobre a revolução e a guerra civil que duraram de julho de 1936 a $1^{\circ}$ de abril de 1939. Ainda assim, com frequência é reproduzida a caracterização equivocada do "Partido Operário de Unificação Marxista" (POUM) como sendo uma organização "trotskista" (ou de "inspiração trotskista"), ao passo que continua relegada ao esquecimento a atuação daqueles - poucos, é verdade - efetivamente ligados ao agrupamento internacional então encabeçado por Leon Trotski, a "Liga Comunista Internacional" (sucessora da "Oposição de Esquerda Internacional" e predecessora da Quarta Internacional).

Compreender a exata relação do POUM com o trotskismo, bem como resgatar as análises e a atuação daqueles que efetivamente se reivindicavam como tal, não só permite desfazer confusões que perduram, mas também trazer à tona aspectos da história dessa revolução que são convenientemente apagados pela narrativa que apresenta a Frente Popular e seus componentes como resolutos heróis antifascistas, derrotados pela "covardia" das nações "democráticas" (especialmente França e Inglaterra) em não intervirem a favor da República. Aspectos esses que revelam uma história muito diferente e permitem explicar de forma mais refinada o(s) porquê(s) dessa trágica derrota. É essa a intenção do presente texto, que se baseia largamente nos trabalhos dos historiadores Pierre Broué e Augustín Guillamón sobre o assunto, bem como em materiais escritos por Trotski e, em menor medida, em outras fontes primárias e secundárias.

\section{As origens do POUM, sua relação com o trotskismo e sua atuação na revolução}

A atuação do POUM ao longo de 1936-39 se tornou bastante conhecida em grande parte graças às memórias do escritor George Orwell (Homenagem à Catalunha, 1938), que integrou uma milícia do partido na Catalunha e, mais recentemente, também ao filme de Ken Loach e Jim Allen, Terra e Liberdade (1995 - que foi em grande parte inspirado em tais memórias). Nessas obras, assim como na produção historiográfica, tal partido é com frequência considerado a "ala esquerda" da Frente Popular - a frente eleitoral formada em 
junho de 1935 entre o socialdemocrata "Partido Socialista Operário Espanhol" (PSOE), o stalinista "Partido Comunista da Espanha" (PCE) e outras organizações, incluindo grupos "republicanos" não socialistas e de caráter de classe burguês. Consequentemente, o POUM também é com frequência apresentado como a "ala esquerda" da Revolução Espanhola. E papel semelhante costuma ser atribuído aos anarcossindicalistas da "Federação Anarquista Ibérica" (FAI), que hegemonizavam a "Confederação Nacional do Trabalho" (CNT), então a maior central operária da Espanha - os quais também vieram a participar da Frente Popular e de seu governo nacional, ocupando inclusive minsitérios.

O POUM de fato possuía uma posição bastante crítica ao PSOE e ao PCE (bem como à sua sucursal catalã, o "Partido Socialista Unificado da Catalunha", PSUC) - as forças que hegemonizavam a Frente Popular, especialmente a partir do golpe militar franquista. Quando teve início a guerra civil, o partido se posicionou contra a estratégia nacional-reformista do stalinismo e da socialdemocracia de lutar primeiro pela República e deixar a revolução socialista para um futuro incerto - estratégia determinada pelo apego do PSOE à ordem capitalista e pela submissão do PCE/PSUC aos interesses sociais da burocracia soviética, de "coexistência pacífica" com o imperialismo.

Nesse sentido, o POUM defendeu publicamente as expropriações de terras e ocupações de fábricas que ocorreram ainda nos primeiros momentos da insurreição contra o golpe, encarando que era necessário derrotar o conjunto da burguesia para impedi-lo. Foi também um defensor dos vários comitês (juntas) que se alastraram como forma de organizar a resistência nas fábricas, bairros, no campo e nos fronts, apontando que eles deveriam se unificar em um poder proletário revolucionário. ${ }^{1}$

Ademais, sua origem remete ao trotskismo, uma vez que foi fundado em setembro de 1935 como fruto da fusão entre a "Esquerda Comunista da Espanha" (ICE) e o "Bloco Operário e Camponês" (BOC). Enquanto o BOC, liderado por Joaquín Maurín, havia sido formado a partir da fusão entre diversas dissidências do PC espanhol e integrava a "Oposição à Internacional Comunista" (também conhecida como "oposição de direita" ou "bukharinista"), a ICE havia surgido em 1930 enquanto seção da Espanha da "Oposição de Esquerda Internacional”, liderada por Leon Trotski (à época de sua fundação, possuía o nome de "Oposição Comunista da Espanha").

Todavia, a fusão da ICE com o grupo de Maurín, em 1935, foi a culminação de uma batalha interna que havia começado no ano anterior, tendo resultado em sua separação da Oposição - à altura renomeada "Liga Comunista Internacional" e em campanha pela fundação da Quarta Internacional. Essa divergência girou em torno da aplicação ou não da tática de "entrismo" no PSOE, então preconizada pela Liga como forma de disputar setores da socialdemocracia que estavam se radicalizando e se afastando do reformismo.

Não obstante os chamados da parte da juventude do PSOE ("Juventudes Socialistas da Espanha") para que os trotskistas adentrassem o partido e o "bolchevizassem", essa

\footnotetext{
${ }^{1}$ Victor Alba \& Stephen Schwartz, Spanish Marxism versus Soviet Communism. A History of the P.O.U.M. in the Spanish Civil War [1988], New Bunswick and London, Transaction Publishers, 2009, edição digital de 2016, p. 106-11.
} 
política de entrismo encontrou forte resistência entre os trotskistas não só na Espanha, mas em várias outras seções da Liga. Andreu Nin, dirigente da organização e antigo secretário de Leon Trotski (nos anos 1920) foi um dos que se opuseram firmemente a ela, defendendo, ao invés, a integração da ICE ao BOC. Por conta de sua postura, foi duramente criticado por Trotski, especialmente por ocupar um cargo de responsabilidade no órgão dirigente da Liga, seu Secretariado Internacional. A defesa de uma integração ao BOC também foi fortemente motivada pela sua oposição ao chamado por uma Quarta Internacional, lançado pela Oposição de Esquerda Internacional a partir de $1933 .{ }^{2}$

Apenas um setor muito minoritário da ICE defendeu essa política dentro do grupo, argumentando que o entrismo no PSOE possibilitaria ganhar amplos setores da sua juventude, uma vez que até mesmo seu então dirigente, Santiago Carillo, era favorável à aproximação com os trotskistas, e que estas se encontravam em plena efervescência após a Revolução das Astúrias (1934). Entre os defensores de tal política se encontrava "Grandizo Munis" (pseudônimo do mexicano Manuel Fernández-Grandizo Martínez), um dos fundadores da ICE e um nome hoje muito apagado na história do trotskismo. Após uma batalha interna, um punhado de militantes organizados em torno de Munis e de "L. Fersen" (pseudônimo de Enrique Fernández Sendón) deixou o grupo em julho de 1935, através de uma curta carta de ruptura assinada por oito nomes. Assim se consumou também a ruptura da Liga com a ICE. ${ }^{3}$

Mas a questão do entrismo no PSOE não era a única divergência entre a ICE e a direção da Liga, uma vez que há nas correspondências entre Trotski e Nin prévias à ruptura uma série de outras divergências importantes, que se acumulavam desde ao menos $1931 \mathrm{e}$ se expressaram em amargas disputas no interior do grupo da Espanha e também entre sua direção e a da então Oposição de Esquerda Internacional. Uma querela em particular sobressaiu: quando Nin hesitou em condenar o dirigente francês Alfred Rosmer após ele ter rompido com a seção francesa da Oposição e tentado criar uma fração em torno de si no interior dela. Outra divergência importante era em relação a sua vontade em estabelecer relações com grupos que a Oposição encarava serem "centristas", como a francesa Gauche Révolutionnaire de la SFIO. Não à toa, logo após sua fundação, o POUM aderiu ao

\footnotetext{
${ }^{2}$ Andy Durgan, "The Spanish Trotskyists and the Foundation of the POUM", Revolutionary History, 4:1-2, versão digital, [s.p.], disponível em https://www.marxists.org/history/etol/document/poum/index.htm, acessado em junho de 2016; Robert J. Alexander, International Trotskyism, 1929-1985: a documented analysis of the movement, Durham, Duke University Press, 1991, p. 685-86 e 691-94.

${ }^{3}$ Luis González, El trotskismo en España. Las organizaciones trotskistas en el Estado español desde 1930 a la actualidad, Madrid, POSI, 2006, p. 43-53. (É necessário apontar que Gonzáles claramente plagiou um texto de Pierre Broué em seu capítulo "La sección bolchevique-leninista de España", por vezes até reproduzindo frases inteiras do original, sem sequer incluir tal texto nas referências de sua obra. Não obstante, é uma obra que apresenta uma síntese valiosa da história do trotskismo na Espanha, mas que deve ser utilizada com cuidado pela possibilidade de conter outros plágios além do detectado. Para a referência ao texto de Broué em questão, ver nota 6). Agustín Guillamón, "Introducción Histórica", in (dir.), Documentación histórica del trosquismo español (1936-1948). De la guerra civil a la ruptura con la IV Internacional [1996], Valencia, Alexandría Proletaria, 2004, p. 15-16. Carta de Fersen y otros camaradas al Comité Ejecutivo de la ICE [1935], in Agustín Guillamón (dir.), Op. cit., p. 36.
} 
chamado Birô de Londres, ou "Centro Marxista Revolucionário Internacional" - um agrupamento internacional composto por grupos como os alemães SAP e KPO e a francesa Gauche Révolutionnaire, o qual Trotski caracterizava igualmente como "centrista". 4

Não bastassem as diferenças sobre como construir um partido revolucionário na Espanha e internacionalmente, o afastamento dos antigos militantes da ICE em relação a Trotski e à Liga Comunista Internacional se aprofundou ainda mais em janeiro de 1936, quando o POUM assinou o manifesto eleitoral da Frente Popular, encabeçada pelo PSOE e pelo PCE. O combate à Frente Popular, que foi a nova roupagem assumida pela linha de colaboração de classes do stalinismo - momentaneamente suspensa pela linha sectária de "classe contra classe", que vigorou de 1928-33 e segundo a qual fascismo e socialdemocracia eram duas faces de uma mesma moeda - era um dos pilares do bolchevismo-leninismo desde os tempos da Oposição de Esquerda russa. Dessa forma, Trotski condenou duramente a postura de seus antigos aliados, classificando-a publicamente como uma "traição".

Com a criação do POUM, basicamente deixou de existir uma organização trotskista na Espanha, tendo "Munis" retornado para o México para visitar sua família e os demais que deixaram a ICE adentrado o PSOE sob a liderança de "Fersen" para aplicarem a linha entrista. O italiano Nicola di Bartolomeo, atuando com o pseudônimo "Fosco", foi então enviado para o país em maio de 1936 para tentar reorganizar uma seção da Liga a partir de Barcelona, junto a sua esposa Victoria Gervasini (pseudônimo "Sonia").

Conforme aponta o historiador Pierre Broué, dada a inexistência de um grupo sólido quando da eclosão da revolução em julho de 1936, Trotski e o Secretariado Internacional da Liga resolveram tentar uma aproximação com o POUM, sob a perspectiva de que o novo momento exigia deixar as velhas diferenças para trás e lutar pela formação de um partido revolucionário - sem, no entanto, abrirem mão de suas críticas ao que consideravam a linha centrista do partido. Nesse sentido, assim que se encerrou a Conferência Internacional da Liga (na realidade, uma primeira tentativa fracassada de fundar a Quarta Internacional), que ocorria em Bruxelas quando a revolução começou, uma delegação foi enviada à Barcelona sob a direção do francês Jean Rous e de seu secretário, o poeta surrealista Benjamin Péret.

Os primeiros contatos com o POUM, em agosto, foram bem sucedidos, apesar da intenção inicial de adentrar o partido como fração ter sido impossibilitada pela negativa da sua direção. Não obstante, Fosco foi encarregado de organizar, junto ao bolcheviqueleninista francês Robert de Fauconnet, a coluna de voluntários internacionais da milícia do POUM, a primeira do tipo a ser formada na Guerra Civil, e que foi batizada "Coluna Internacional Lenin”. O Hotel Falcón lhes foi entregue pelo partido para ser seu quartel-

\footnotetext{
${ }^{4}$ Pelai Pagès, El movimiento trotskista en España, 1930-1935: La izquierda comunista de España y las disidencias comunistas durante la Segunda República, Barcelona, Península, 1977. Leon Trotsky, "Two Articles on Centrism", Class Struggle, 4:8, agosto de 1934, [s.p.]. Disponível em https://www.marxists.org/archive/trotsky/1934/02/centrism.htm. Acessado em junho de 2016. Robert J. Alexander, Op. cit., p. 260-61.

${ }^{5}$ Leon Trotski, “A traição do 'Partido Operário da Unificação Marxista' espanhol” [1936], in Revolução Espanhola - compilação, São Paulo, Iskra, 2014, p. 158-60.
} 
general. Ainda em agosto, a Coluna partiu para a frente de Huesca, onde Fauconnet foi morto em combate, no começo do mês seguinte. Na retaguarda, "Sonia" foi encarregada de operar a rádio do partido em Barcelona e de traduzir seus boletins para outras línguas, com o auxílio de outros trotskistas. O próprio Trotski foi convidado por Nin a escrever regularmente para o periódico nacional do POUM (o que aceitou de bom grado) e também a se mudar para Barcelona (convite que não pôde se concretizar por impedimento do governo).

Entretanto, ressalta Broué, muitos trotsksitas recém-chegados do estrangeiro agiam de maneira arrogante ante a militância do POUM, constantemente denunciando sua "traição" de ter apoiado a Frente Popular, o que paulatinamente azedou as relações. A isso se somou ainda a constante pressão exercida por enviados de outros partidos do Birô de Londres para que o POUM se afastasse dos bolchevique-leninistas. Exemplo das crescentes tensões entre estes e a direção do POUM, o partido não permitiu que a bandeira da Quarta Internacional (então o círculo vermelho cruzado por um raio em formato de quatro) fosse desfraldada no enterro de Fauconnet. ${ }^{6}$

Ademais, as perspectivas de avançar para a construção de um partido revolucionário com base no POUM foram definitivamente frustradas pelo comprometimento cada vez maior do partido com a política da Frente Popular. A fusão do BOC e da ICE fizeram do POUM um partido bastante dividido, o que se refletia em sua política. Broué exemplificou essa divisão apontando seus dois extremos. Na seção regional de Madrid, onde predominavam antigos membros da ICE, cooperava-se ativamente com os trotskistas e um enorme retrato de Trotski figurava em sua sede. Em sua publicação local, criticava-se duramente o caráter burguês do governo republicano e se defendia a necessidade de avançar a revolução através da construção de conselhos proletários revolucionários, além de se criticar o caráter contrarrevolucionário do stalinismo e defender uma perspectiva internacionalista. Ademais, era possível encontrar pelos muros da cidade o então símbolo da Quarta Internacional.

Já na seção regional do Levante, dominada por antigos membros do BOC, se declarava apoio irrestrito ao governo republicano, tratava-se jocosamente os acusados nos Processos de Moscou, então em curso, e se condenava internamente o "radicalismo" da regional madrilenha. E, ainda que Nin tenha ascendido à direção do partido após a prisão de Maurín (que se encontrava em uma cidade onde o levante franquista triunfou rapidamente) ele era visto com desconfiança pelos antigos quadros do BOC, maioria no POUM, e que constantemente o pressionavam para a direita no Comitê Central. ${ }^{7}$

\footnotetext{
${ }^{6}$ Referências para este e os três parágrafos anteriores: Pierre Broué, "Trotski e a guerra civil espanhola" [1975], in Leon Trotski, A Revolução Espanhola - compilação, São Paulo, Iskra, 2014, p. 341-43 (há também uma versão em castelhano: Pierre Broué, "Trotsky y la guerra civil en España" [1975], in La revolución española, vol. 2, Barcelona, Fontanella, 1977, disponível em

https://www.marxists.org/espanol/broue/1975/trotsky_y_la_guerra_civil_en_esp.htm, acessado em dezembro de 2016). Frank Mintz y Miguel Peciña, Los Amigos de Durruti, los trotsquistas y los sucesos de mayo, Madrid, Campo Abierto, 1978, p. 39-41.

${ }^{7}$ Referência para este e o parágrafo anterior: Pierre Broué, Op. cit., p. 344-47.
} 
Fruto dessa heterogeneidade, que pendia para a antiga ala "bloquista", e do receio comum ao conjunto dos membros do partido em não se "isolarem" do resto da esquerda, em particular da CNT/FAI, o POUM acabou por integrar o governo local catalão (a Generalitat) em outubro de 1936, tendo Nin assumido o cargo de Ministro da Justiça - sob protestos da regional madrilenha, que quase rompeu com o partido. A Generalitat foi reorganizada como forma da Frente Popular reassumir o controle da região, que desde julho na prática se encontrava nas mãos do dos vários comitês locais de autogestão e em especial do "Comitê Central das Milícias Antifascistas" (ainda que esse órgão fosse formalmente submetido ao governo local), criado para unificar as milícias surgidas em julho. Também em outubro, Largo Caballero (PSOE), Presidente do Conselho de Ministros, promulgou um decreto de "militarização" das milícias, visando a formação de um exército nacional unificado. Travava-se de um esforço generalizado de reconstruir o Estado burguês, deixado em frangalhos pela insurreição de julho e pela deserção nas tropas, que passaram para o lado de Franco.

O governo central e os enviados de Moscou, que passaram a chegar à Espanha em grandes levas a partir de novembro, viam os comitês e as milícias autônomas como um empecilho para sua aliança com a burguesia liberal e para o tão almejado apoio da França e da Inglaterra, cujos governos viam a Frente Popular com enorme desconfiança, enxergando na Espanha o "perigo vermelho" da revolução. Dessa forma, sob crescente pressão moscovita, a dualidade de poderes criada a partir de julho foi sendo paulatinamente destruída por dentro, pela pressão do PSOE e PCE e pela capitulação da CNT/FAI e do POUM às mesmas.

Em abril de 1937 o governo central enviou tropas à Catalunha para remover o controle da CNT/FAI sobre as alfândegas, quase precipitando um conflito armado - evitado apenas pela decisão dos anarcossindicalistas de entregarem os entrepostos. Chegadas em Barcelona, as tropas demandaram que as milícias locais entregassem as armas e, ante sua negativa, uma série de enfrentamentos pontuais ocorrem pelas ruas da cidade. A situação se tornou explosiva quando, em 3 de maio, um enviado do PSUC tentou retirar da CNT/FAI o controle da central telefônica, que havia sido expropriada da empresa American Telegraph \& Telephone (EUA). Na sequência da tentativa malsucedida, barricadas se espalharam por toda a cidade e teve lugar uma verdadeira guerra civil dentro da guerra civil - ou, mais precisamente, um aprofundamento do processo revolucionário e da situação de dualidade de poderes. Com a cidade nas mãos dos trabalhadores, a 4 de maio Caballero e os "anarcoministros" Garcia Oliver e Frederica Montseny (CNT/FAI) enviaram desde Madrid mensagens apaziguadoras em nome do governo central, ao que o Comitê Regional da CNT/FAI respondeu com um chamado ao armistício. Após uma resistência inicial, o POUM aderiu ao chamado de armistício no dia seguinte.

$\mathrm{Na}$ sequência do armistício, a Generalitat decidiu pela dissolução do Comitê Central das Milícias Antifascistas e dos comitês autogestionados. A CNT/FAI apoiou a proposta e o POUM, após uma oposição inicial, também acabou por aderir, mais uma vez seguindo atrás da política da CNT/FAI, sob o argumento de não se "isolar" das bases dela. Com tais medidas, se fortaleceu o governo da Frente Popular em detrimento dos órgãos de

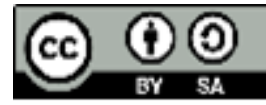


dualidade de poder criados a partir da insurreição de julho. E não foram medidas meramente legais, uma vez que foram implementadas na base de profunda repressão policial às vozes mais radicais no interior da CNT, bem como ao POUM - que o PCE, à altura já completamente sob o controle dos enviados moscovitas, especialmente do dirigente italiano Palmiro Togliatti, exigia que fosse posto na ilegalidade. Ao longo de maio e dos meses seguintes, diversos revolucionários foram presos sob as mais diversas acusações - as quais eram frequentemente falsas. E, à ação governamental, também se somou uma intensa ação de agentes da NKVD, da qual o próprio Nin foi vítima, tendo sido sequestrado em julho, torturado, morto e esquartejado. Durante certo tempo, os stalinistas que, além de frequentemente acusarem o POUM de ser "trotskista", também o acusavam de ser "quinta coluna" - responderam cinicamente às indagações sobre o paradeiro de Nin, dizendo que ele provavelmente se encontrava em Berlim.

Ante a negativa de Caballero em ilegalizar o POUM, os stalinistas, coordenados pelos enviados de Moscou, arquitetaram um golpe que o removeu do poder e permitiu que assumisse Juan Negrín, representante da ala direita do PSOE e muito mais aberto às demandas soviéticas. Sob Negrín, a contrarrevolução foi consolidada, através do esmagamento das vozes mais radicais, dos organismos proletários autônomos e da reconstrução de um exército nacional unificado sob comando da Frente Popular. O POUM foi posto na ilegalidade e muitos de seus membros foram presos, tendo tantos outros tido que adentrarem a clandestinidade para fugirem do governo e dos assassinos enviados por Moscou. ${ }^{8}$ Nos meses que se seguiram, o partido passou por uma intensa crise interna, decorrente dos balanços das suas ações de seguidismo à CNT/FAI e, consequentemente, à Frente Popular ${ }^{9}$.

\section{Trotski, os "bolchevique-leninistas" e suas análises e atuação}

Desde seu exílio na Noruega, Trotski escreveu intensamente sobre os eventos na Espanha. Enfatizando as lições da sua Teoria da Revolução Permanente acerca da impossibilidade da burguesia periférica cumprir as tarefas nacional-democráticas clássicas (reforma agrária, independência nacional, democracia republicana), uma vez que é umbilicalmente ligada aos capitais imperialistas e às velhas elites agrárias, ele condenou duramente a politica de colaboração de classes da Frente Popular, que levava o proletariado a defender a ordem burguesa, supostamente para fazer avançar ditas tarefas. ${ }^{10}$

Buscando caracterizar de forma mais precisa o governo, Trotski afirmou que a Frente Popular era a "sombra da burguesia", no sentido que ela não era composta e nem

\footnotetext{
${ }^{8}$ Referências para este e os quatro parágrafos anteriores: Ibid., p. 354-55. Victor Alba \& Stephen Schwartz, Op. cit., p. 180-81. M. Casanova [Mieczyslaw Bortenstein], Espanha abandonada. Como Stalin abriu as portas a Franco [1939], Lisboa, Antídoto, 1977, p. 84-99 (há também uma versão em castelhano: M. Casanova [Mieczyslaw Bortenstein], El Frente Popular abrió las puertas a Franco [1939], disponível em http://www.marxistsfr.org/espanol/bortenstein/1939/frente/index.htm, acessado em dezembro de 2016).

${ }^{9}$ Pierre Broué, Op. cit., p. 355. Luis González, Op. cit., p. 91.

${ }^{10}$ Leon Trotski, A Revolução Espanhola - compilação, op. cit., passim.
} 
mesmo apoiada pelo grosso da burguesia nativa da Espanha, que havia passado em peso para o lado de Franco ante a ameaça de revolução social. Mas que, não obstante essa ausência, os "advogados da burguesia" (Azaña, Companys etc.) e os stalinistas, socialdemocratas e anarquistas que o compunham cumpriam o papel de subordinar o proletariado aos "princípios da revolução democrática, isto é, da inviolabilidade da propriedade privada" - cumprindo, portanto, valioso serviço à burguesia pró-Franco ${ }^{11}$.

Dessa forma, ele defendeu a perspectiva de que a política de aliança com a burguesia em detrimento da revolução social em curso levaria à derrota na própria luta contra Franco. Segundo suas análises, a tarefa política central era unificar os vários comitês revolucionários já existentes, formando um comando central democraticamente eleito e que dirigisse a classe trabalhadora à expropriação da burguesia, o que serviria de exemplo para os trabalhadores nos territórios sob controle franquista, enfraquecendo Franco sobremaneira. No mesmo sentido, defendia a bandeira de autodeterminação do Marrocos, como forma de golpear decididamente a burguesia que apoiava Franco e debilitar o principal bastião militar franquista, de onde vinham as tropas mais bem treinadas e experientes, bem como defendia o direito à autodeterminação das várias nacionalidades oprimidas no interior do Estado espanhol. ${ }^{12}$

Apesar de Trotski ter acompanhado com bastante atenção os eventos na Espanha, enviando grande volume de artigos e cartas para seus camaradas mundo afora, no mês de agosto de 1937 o governo norueguês, sob pressão de Moscou, o submeteu à prisão domiciliar e cortou toda sua comunicação. Dessa forma, ainda que tenha continuado a produzir reflexões sobre o processo revolucionário, foi apenas no começo de janeiro de 1938, quando já se encontrava em seu novo exílio no México, que Trotski pôde enviar tais materiais para publicação e retomar sua intervenção pública.

Seguindo à risca a linha defendida por Trotski, os trotskistas que atuavam na Espanha criticavam não só a política de colaboração de classes da Frente Popular, considerada contrarrevolucionária, como também as vacilações do POUM ante ela, especialmente sua adesão ao governo da Generalitat, em outubro de 1936. Se autodenominando "bolchevique-leninistas", como faziam então a maior parte dos aliados de Trotski ("trotskista" era uma nomenclatura pejorativa, usada pelos stalinistas para classificarem qualquer adversário que fosse no interior do movimento comunista, eles não só atuaram militarmente na Coluna Internacional Lenin, como realizarem propaganda entre os círculos radicais próximos ao POUM e chegaram até a se ofereceram para cooperarem na organização de um levante revolucionário no Marrocos, junto a uma organização independentista marroquina - mas Caballero, a quem chegaram por intermédio do POUM, recusou a proposta por medo de levantar a ira da França, que também dominava a região. Sua atividade, todavia, foi muito limitada por seu tamanho reduzido - não mais de 50

\footnotetext{
${ }^{11}$ Leon Trotski, "Lições da Espanha: última advertência" [1937], in A Revolução Espanhola, op. cit., p. 246-47.

${ }^{12}$ Leon Trotski, A Revolução Espanhola - compilação, op. cit., passim.
} 
militantes, de acordo com as estimativas de Frank Mintz e Miguel Pecinã - e o fato de muitos serem estrangeiros (italianos, franceses, belgas etc.). ${ }^{13}$

Na sequência do decreto da militarização, que suprimiu as milícias autônomas em prol da criação de um exército nacional, a Coluna liderada pelos "bolcheviques-leninistas" rachou, uma vez que também atuavam em seu interior militantes "bordiguistas" (ligados ao comunista esquerdista italiano, Amadeo Bordiga) que se negaram de imediato a manterem a cooperação com o POUM a partir de então. Conforme relata o historiador Augustín Guillamón, com a posterior dissolução da Coluna Internacional Lenin, ainda em outubro, muitos "bolchevique-leninistas" estrangeiros partiram da Espanha, inclusive o representante do Secretariado da Liga Comunista Internacional, Jean Rous. Já aqueles que permaneceram no país requisitaram adentrarem no POUM como fração, mas tiveram o pedido rejeitado, uma vez que Nin declarou que só poderiam adentrar o partido individualmente e após abdicarem publicamente das acusações que a Liga e Trotski haviam feito contra a organização. Não obstante, alguns seguiram atuando como uma fração secreta no interior do partido até maio de 1937, quando a adesão do POUM à contrarrevolução levou sua direção a realizar uma série de expurgos em suas próprias fileiras (tal qual a CNT/FAI), previamente a um congresso partidário que nunca chegou a ser realizado, em decorrência da repressão da qual a organização também foi vítima ${ }^{14}$.

Impossibilitados de adentrarem no POUM como fração, os "bolchevique-leninistas" se organizaram no diminuto "Grupo Bolchevique Leninista" (GBL), liderado por Fosco e que publicava um jornal em francês, Le soviet. Esse grupo, entretanto, logo se viu dividido, por conta da defesa de Fosco de que se deveria entrar no POUM mesmo que não fosse possível a formação de uma fação oficial, preconizando uma atuação enquanto fração "de fato" - política que alguns viram como "liquidacionismo". Também gerou polêmicas nas fileiras do GBL a filiação de Fosco à ruptura operada por Raymond Mollinier e Pierre Frank na seção francesa da Liga naquele mesmo mês de outubro, formando o Parti Communiste Internationaliste. O grupo de Mollinier e Frank se reivindicava adepto da Liga, mas oposto a seu órgão dirigente, o Secretariado Internacional. Ele colocou seu jornal à disposição do grupo de Fosco e o próprio Mollinier viajou à Barcelona para angariar solidariedade entre os "bolchevique-leninistas" que lá se encontravam.

Ante as crescentes tensões no interior do GBL, entre Fosco e aqueles mais alinhados ao Secretariado Internacional da Liga, então agrupados ao redor de Erwin Wolf, surgiu em novembro a "Seção Bolchevique-leninista da Espanha" (SBLE), impulsionada graças ao retorno do México do antigo dirigente da ICE, Grandizo Munis. Mas a SBLE só ganhou volume em janeiro de 1937, quando parte dos membros do GBL a ela aderiram, deixando Fosco bastante isolado. Segundo as estimativas dos mencionados Mintz e Peciña, em maio daquele ano o GBL contava com meros 7 ou 8 militantes, enquanto a SBLE contava com não mais do que 20. Em relação à SBLE, todavia, Guillamón - que teve contato com entrevistas de ex-membros - afirma que eram então cerca de 30. Não obstante seu tamanho

\footnotetext{
${ }^{13}$ Luis González, Op. cit., p. 68-69. Frank Mintz y Miguel Peciña, Op. cit., p. 39-41.

${ }^{14}$ Ibid., p. 72-73.
}

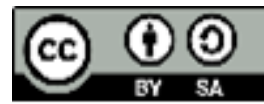


evidentemente diminuto, a partir de abril de 1937 a SBLE foi capaz de publicar o jornal La Voz Leninista e passar distribuir panfletos pelas ruas de Barcelona, contanto com o auxílio de anarcossindicalistas para imprimirem tais materiais. ${ }^{15}$

Igualmente impossibilitado de atuar enquanto fração no interior do POUM, o grupo dirigido por Munis e por outros quadros experientes, tais como como o mencionado Wolf, Adolfo Carlini e Hans Freund (pseudônimo "Moulin"), se tornou mais numeroso e com maiores capacidades de publicação do que o GBL, passando a atuar sobre as bases do POUM e também a desenvolver uma série de atividades entre as bases da CNT/FAI, inclusive colaborando com o agrupamento anarquista "Amigos de Durruti". Tal agrupamento era uma ala esquerda da CNT, que criticava sua adesão ao governo da Frente Popular e às medidas de supressão das juntas revolucionárias, tendo sido nomeado em homenagem a Buenaventura Durruti, anarcossindicalista que dirigiu uma coluna militar de linha política radical e que foi morto em combate em novembro de 1936, sem que até hoje haja certeza se ele caiu por fogo inimigo ou se foi sordidamente eliminado por fogo "republicano",

Apesar de amplamente ignorado pela história do movimento trotskista, a SBLE era o grupo "oficial" da Liga Comunista Internacional na Espanha, cujos documentos centrais foram resgatados do esquecimento e compilados por uma equipe de historiadores coordenada por Guillamón (a qual realizou tarefa semelhante em relação ao agrupamento Amigos de Durruti). Sua linha política central, conforme expressa em um manifesto de julho de 1937, era de denúncia à colaboração do POUM e da CNT/FAI com o governo do PSOE / PCE e de agitação pela formação de uma frente única proletária capaz de tomar o poder e expropriar a burguesia, de forma a vencer a guerra civil através do triunfo da revolução social ${ }^{17}$.

Durante o levante de maio em Barcelona, a SBLE e os Amigos de Durriti foram os únicos a panfletarem convocando a formação de conselhos revolucionários ("Comitês de Defesa Revolucionária", no caso da SBLE), que assumissem o controle da cidade e se espalhassem por toda a Catalunha. O panfleto circulado pela SBLE a partir do dia 4 (segundo dia do conflito) entoava vivas à "ofensiva revolucionária" e conclamava por "nada de compromissos", chamando por uma "greve geral de todas as indústrias que não trabalhem para a guerra" como forma de conquistar a "demissão" do "governo revolucionário". Ao mesmo tempo, o material defendia o desarmamento das tropas da Frente Popular que atacavam Barcelona e o armamento do proletariado, reafirmando a linha

\footnotetext{
${ }^{15}$ Referência para este parágrafo e os dois anteriores: Augustín Guillamón, Op. cit., p. 18-21, 22 e 33. Frank Mintz y Miguel Peciña, Op. cit., p. 41.

${ }^{16}$ Mintz e Pecinã contestam que tenha havido qualquer colaboração entre os "bolchevique-leninistas" e os "Amigos de Durruti”. Todavia, eles se baseiam apenas na ausência de indícios de tal colaboração nas páginas dos periódicos dos dois grupos, ao passo que Guillamón resgata entrevistas com antigos dirigentes "bolchevique-leninistas" para afirmar que houve tentativas de aproximação política e de coordenação de atividades. Frank Mintz y Miguel Peciña, Op. cit., p. 43. Augustín Guillamón, Op. cit., p. 21-22.

${ }^{17}$ A Posição dos bolchevique-leninistas espanhóis [1937], in Leon Trotski, A Revolução Espanhola, op. cit., p. 205-07.
} 
central de Trotski, segundo a qual "apenas o poder proletário pode assegurar a vitória militar"18. Ao fim do conflito, o balanço que os "bolchevique-leninistas" (e também os Amigos de Durruti) fizeram do armistício e da posterior dissolução dos vários comitês autogestionários foi de que era um triunfo da contrarrevolução, com a qual a CNT/FAI e o POUM haviam pactuado. ${ }^{19}$

Apesar da SBLE ter crescido através de seu trabalho no interior da CNT e nas bases do POUM, a repressão desencadeada a partir de maio de 1937 sob o comando de Negrín e dos stalinistas também se estendeu aos "bolchevique-leninistas", que tiveram os dirigentes Hans Freund e Erwin Wolf assassinados em meados de 1937 e Munis, Alfonso Rodríguez e Antonino Alvarez presos em fevereiro de 1938, sob falsas acusações de terem assassinado um agente da NKVD. Após meses de prisão, esses conseguiram fugir pouco antes das tropas franquistas terem tomado Barcelona. Eles atravessaram a fronteira para a França e lá se juntaram a tantos outros camaradas seus que também foram forçados ao exílio, junto aos quais reorganizaram o grupo em Paris. Mas muitos foram forçados a novo exílio, dessa vez para o México, quando da tomada da França pelos nazistas. Dessa forma, passaram a existir dois grupos de "bolchevique-leninistas" espanhóis ao longo dos anos seguintes a 1939: o "Grupo Espanhol da Quarta Internacional no México", dirigido por Munis e Péret, em colaboração muito próxima com a viúva de Trotski, Natalia Sedova; e o "Grupo Comunista Internacionalista - Seção espanhola da Quarta Internacional”, atuante na França. ${ }^{20}$

No espaço de tempo entre a prisão de Munis e dos outros dirigentes da SBLE e a derrota da revolução, a direção do grupo foi assumida pelo polonês Mieczyslaw Bortenstein, que atuou na Espanha de 1936 a 1939 em uma fábrica ocupada, sob o pseudônimo "M. Casanova". Sob sua direção, ainda que atuando de forma clandestina, a SBLE conseguiu incidir na crise pela qual passou o POUM ao ter pagado um enorme preço pelos serviços que prestou à contrarrevolução em maio de 1937, bem como continuou a atuar no interior da CNT, apontando os erros de sua direção ao se submeter à Frente Popular e enfatizando o que encaravam ser a única alternativa viável para derrotar Franco: a revolução socialista.

Ao fugir para a França após o avanço franquista sobre Madrid e Barcelona (26 de janeiro de 1939), ainda antes do golpe de Estado de Miaja-Casado - que removeu Negrín do poder e propôs um armistício a Franco, em março de 1939 - Casanova proferiu uma palestra sobre sua experiência e a de seus camaradas, a qual foi posteriormente publicada como livro. Ainda em 1939, todavia, ele foi preso por agentes alemães e terminou assassinado no campo de concentração de Auschwitz, em 1942. ${ }^{21}$

Seguindo a linha segundo a qual apenas a revolução socialista poderia ter derrotado Franco, Casanova argumentou que "Não o foram nem o socialismo nem o marxismo que fracassaram em Espanha, mas aqueles que covardemente o traíram" - uma vez que, em suas palavras, "foi a aplicação da fórmula "primeiro ganhar a guerra, depois fazer a

\footnotetext{
${ }^{18}$ Apud Frank Mintz y Miguel Peciña, Op. cit., p. 41-42.

${ }^{19}$ Augustín Guillamón, Op. cit., p. 22. Luis González, Op. cit., p. 82.

${ }^{20}$ Ibid., p. 94 e p. 96 . Augustín Guillamón, Op. cit., p. 23-24.

${ }^{21}$ Luis González, Op. cit., p. 88.
} 
revolução' que conduziu, como o tínhamos previsto já em 1936, à perda, primeiro da revolução, depois da guerra". Ainda segundo seu balanço, "a tragédia espanhola é mais um crime na lista da burocracia stalinista, que esmagou o movimento revolucionário, assassinou os seus melhores combatentes, desmoralizou, através da sua nojenta política de servilhismo para com o capital internacional, dito democrático, o heroico proletariado deste país". 22

Da mesma forma, desde Paris, os exilados da antiga SBLE que lá chegaram ao longo de 1939 também publicaram balanços nos quais apontavam a responsabilidade da política stalinista de colaboração de classes na derrota não só do proletariado da Espanha, mas da própria causa republicana, dita "democrático-burguesa". ${ }^{23} \mathrm{E}$ o debate sobre as "lições" da Revolução Espanhola não ficaram restritos apenas aos "bolchevique-leninistas" que nela atuaram, conforme demonstra o livro escrito por Felix Morrow, quadro dirigente do Socialist Workers Party dos EUA, pertencente à Liga Comunista Internacional, e que circulou amplamente entre os "bolchevique-leninistas" mundo afora, apresentando um balanço análogo ao de seus camaradas do outro lado do Atlântico (Revolution and Counter Revolution in Spain, 1938) ${ }^{24}$.

Trotski, por sua vez, a partir de seu novo exílio no México, também teceu balanços similares, enfatizando tanto a inviabilidade do programa etapista de revolução "democrático-burguesa" e de colaboração de classes do stalinismo, então sintetizado na política de construir "Frentes Populares" em todo o mundo, quanto a necessidade urgente de se construir partidos revolucionários capazes de liderarem o proletariado à vitória com base em um programa socialista.

Dessa forma, viu na trágica experiência da Revolução Espanhola mais uma prova do caráter contrarrevolucionário do stalinismo, cuja estratégia etapista de relegar a revolução socialista para um futuro incerto e de priorizar uma impossível revolução "democráticoburguesa" não era senão uma falsa teoria derivada dos interesses materiais da burocracia soviética, de coexistência "pacífica" com o imperialismo. E viu também o enorme prejuízo que o "centrismo" pode gerar para a causa da emancipação do proletariado, uma vez que o POUM, ao invés de lutar decididamente contra a conciliação de classes - que levou a classe trabalhadora da Espanha para o matadouro franquista - se deixou ser levado a reboque pela Frente Popular, baseado na premissa de não se "isolar" das forças que a compunham, em especial a CNT/FAI. ${ }^{25}$

\footnotetext{
${ }^{22}$ M. Casanova [Mieczyslaw Bortenstein], Op. cit., p. 9, 65 e 13, respectivamente.

${ }^{23}$ Luis González, Op. cit., p. 90-91.

${ }^{24}$ Felix Morrow, Revolution and Counter Revolution in Spain [1938], London, New Park Publications, 1963, disponível em https://www.marxists.org/archive/morrow-felix/1938/revolution-spain/, acessado em junho de 2016 (há também uma versão em castelhano: Felix Morrow, Revolución y contrarrevolución en España, Madrid, Akal, 1977).

${ }^{25}$ Leon Trotski, "Classe, partido e direção. Por que o proletariado espanhol foi derrotado? Questões de teoria marxista" [1940], in _. A Revolução Espanhola, op. cit., p. 267-277. Trotski ainda estava terminando tal artigo quando foi atacado pelo agente stalinista Ramón Mercader, em 20 de agosto de 1940, vindo a falecer no dia seguinte.
} 
Centrismo esse que recebeu apoio entre setores da própria Liga Comunista Internacional, impactando assim a construção da Quarta Internacional, que só foi efetivamente fundada em 1938. Tais setores foram aqueles reunidos sob a liderança do dirigente belga George Vereeken, do dirigente holandês Henk Sneevliet, além do dissidente bolchevique Victor Serge. Suas posições pró-POUM foram duramente condenadas por Trotski e combatidas com o fim de solidificar os quadros da futura internacional, mas a ruptura com eles reduziu consideravelmente as fileiras do movimento pró Quarta Internacional $^{26}$. Foi refletindo sobre experiências como a fracassada Revolução Espanhola que Trotski enfatizou ainda mais a importância do fator subjetivo da liderança política na luta pelo socialismo, afirmando no programa de fundação da Quarta Internacional (Programa de Transição, 1938) que "Tudo depende do proletariado, ou seja, antes de mais nada, de sua vanguarda revolucionária. A crise histórica da humanidade reduz-se à crise da direção revolucionária"27. Uma perspectiva incompatível com aquela do POUM e de seus apoiadores internacionais, de buscar "substitutos" para o partido marxista.

Críticas similares ao papel "vacilante" e "capitulador" do POUM também foram realizadas nos balanços de Casanova, Morrow e dos membros da SBLE no exílio. Esses veicularam suas críticas através das edições de La Voz Leninista produzidas no exílio, mas um de seus militantes em particular produziu um balanço próprio em forma de livro, que ganhou maior notoriedade e sobrevivência histórica. Trata-se de Munis, que se debruçou sobre o processo revolucionário, seus fatores sociais e seus sujeitos políticos em um livro escrito entre 1943 e 1947, durante seu exílio no México, e que foi publicado em 1948.

Ainda que convergindo em termos gerais com os demais balanços mencionados, com na crítica à política reformista / etapista de colaboração de classes do PSOE e do PCE, bem como à política "centrista" do POUM, o livro de Munis reflete algumas mudanças importantes em suas posições políticas anteriores - especialmente em relação à caracterização do stalinismo e da URSS. ${ }^{28}$ Pois, ao longo dos anos 1940, Munis se afastou cada vez mais do trotskismo, processo que culminou em sua ruptura com a Quarta Internacional em novembro de 1948 e em sua adesão à chamada "esquerda comunista", após alguns anos atuando em conjunto com Péret e Sedova como uma voz crítica à direção da organização ${ }^{29}$.

\footnotetext{
${ }^{26}$ Pierre Broué, Op. cit., p. 356-57.

${ }^{27}$ Leon Trotsky, O programa de transição para a revolução socialista [1938], São Paulo, Sundermann, 2008, p. 13.

${ }^{28}$ G. Munis [Manuel Martínez], Jalones de derrota promesa de victoria. Critica y teoría de la revolución española, 1930-1939. Obras completas, Tomo IV, Brenes, Muñoz Moya Editores Extremeños, 2003.

${ }^{29}$ As principais divergências do trio com o restante da Quarta Internacional foram acerca da defesa dos 18 militantes e dirigentes da seção dos EUA julgados em 1941 por acusações de quererem derrubar violentamente o governo e causar insubordinação no seio das forças armadas, a qual eles encararam ter sido conduzida de forma oportunista, por conta dos acusados terem se esquivado de declararem abertamente certas posições. Também denunciaram as arbitrariedades estatutárias feitas ante o $2^{\circ}$ Congresso Mundial, de novembro de 1948, para favorecer aqueles alinhados às posições da seção dos EUA (as previsões de crise econômica iminente e abertura de um período revolucionário). Nesse congresso, o trio se aliou ao grupo "terceiro campista" de Max Shachtman (o Workers Party dos EUA), que defendia não mais ser possível
} 


\section{Conclusão}

A experiência da Revolução Espanhola, confirmando amargamente os aspectos centrais da Teoria da Revolução Permanente, viu tanto a burguesia espanhola, umbilicalmente ligada às velhas elites fundiárias, quanto os imperialismos francês e inglês, preferirem a ditadura de Franco e seu bando nacionalista, católico-conservador e fascista à única alternativa viável para derrota-lo: a revolução proletária socialista, que tomaria suas terras, ocuparia suas fábricas, libertaria o Marrocos, garantiria autonomia às nacionalidades oprimidas e levaria o proletariado ao poder, além de dar enorme impulso à revolução socialista mundial. A Frente Popular, baseada em um impossível projeto de conciliar os interesses burgueses com os interesses proletários, foi pouco a pouco cedendo aos primeiros em detrimento dos segundos, visando uma utópica aliança entre o proletariado revolucionário e aqueles diretamente afetados pela revolução, os capitalistas.

Dessa forma, a revolução social que erguera as milícias anti-franquistas e mobilizara dezenas de milhares de socialistas ao redor do globo para irem lutar na Espanha (cerca de 40 mil voluntários estrangeiros, ao passo que o bando franquista mobilizou apenas cerca de mil $^{30}$ ) foi esmagada desde seu interior. E, vendo seus interesses cada vez menos representados pelo governo da Frente Popular, os trabalhadores que forneciam suas próprias vidas à causa republicana pouco a pouco perderam sua efervescência inicial, o que levou à drástica queda no número de combatentes (especialmente após o decreto da "militarização" e o golpe de Negrín) e também à diminuição do ritmo de produção pelas fábricas ocupadas, incluindo as envolvidas no esforço de guerra. ${ }^{31}$

O relato de Casanova ante o verdadeiro "êxodo" que se seguiu à queda de Barcelona é bastante representativo da falsa unidade que a Frente Popular fingia representar ao, na

caracterizar a URSS como um "Estado operário burocraticamente degenerado". Eles também criticaram duramente a onda de apoio a Josep Tito e ao regime iugoslavo, que tomou conta das fileiras trotskistas nos meses seguintes a tal congresso, quando aquele rompeu relações com Stalin e com Moscou - nessas críticas foram acompanhados pela liderança da seção inglesa. Apesar de Sedova e Perét terem apoiado o grupo que Munis fundou após deixar a Quarta Internacional - o "Grupo Comunista Internacionalista da Espanha" (no México) - eles próprios só romperam em maio de 1951, após a liderança internacional ter caracterizado os países do Leste Europeu como "Estados operários burocraticamente deformados". Um acordo sólido que unia o trio era a crítica de que reconhecer que o stalinismo havia expropriado a burguesia em parte do globo, apesar de sua orientação contrarrevolucionária, levava "necessariamente" a reduzir o trotskismo a uma mera "ala esquerda" dele - posição que de fato passou então a ser defendida por parte da nova liderança internacional, em particular Michel Pablo (pseudônimo do grego radicado na França Michalis Raptis). Agustín Guillamón Iborra, "Munis, vie et oeuvre d'un révolutionnaire méconnu", Cahiers Leon Trotsky 50, Paris, mai de 1993, p. 85-101. Sam Borstein e Al Richardson, The War and the International: A History of the British Trotskyist Movement, 1937-1949, London, Socialist Platform, 1986, p. 215. Marcio Lauria Monteiro, "O movimento trotskista internacional e as revoluções do pós-guerra", Outubro 27, novembro de 2016, disponível em http://outubrorevista.com.br/o-movimento-trotskista-internacional-e-as-revolucoes-do-posguerra/, acessado em dezembro de 2016.

${ }^{30}$ Eric J. Hobsbawm, A Era dos Extremos. O breve século XX. 1914-1991, São Paulo, Companhia das Letras, 1995, p. 161.

${ }^{31}$ Luis González, Op. cit., p. . M. Casanova [Mieczyslaw Bortenstein], Op. cit., p.74-76 e 95-99. 
realidade, submeter o proletariado (e sua revolução socialista) à burguesia "liberal" e ao imperialismo "democrático": "por um lado, os burgueses de esquerda e os burocratas aburguesados, que viajavam em belos automóveis ou, no pior dos casos, nos pequenos Citroen; por outro lado, os operários, camponeses e combatentes, que seguiam a pé"32. Que aos 80 anos da Revolução Espanhola seja lembrada a lição de que não há caminho intermediário possível entre a dominação burguesa e a revolução socialista, sendo a colaboração de classes um uma via incompatível com a emancipação do proletariado e das demais classes subalternas.

\section{Referências bibliográficas}

Impressas

A Posição dos bolchevique-leninistas espanhóis [1937], in Leon Trotski, A Revolução Espanhola, op. cit., p. 205-07.

Agustín Guillamón, "Introducción Histórica”, in_(dir.), Op. Cit., p. 15-31.

Agustín Guillamón Iborra, "Munis, vie et oeuvre d’un révolutionnaire méconnu" Cahiers Leon Trotsky n. 50, Paris, mai de 1993, p. 85-101.

Carta de Fersen y otros camaradas al Comité Ejecutivo de la ICE [1935], in Agustín Guillamón (dir.), Documentación histórica del trosquismo español (1936-1948). De la guerra civil a la ruptura con la IV Internacional [1996], Valencia, Alexandría Proletaria, 2004, p. 36.

Eric J. Hobsbawm, A Era dos Extremos. O breve século XX. 1914-1991, São Paulo, Companhia das Letras, 1995.

Felix Morrow, Revolución y contrarrevolución en España, Madrid, Akal, 1977.

Frank Mintz y Miguel Peciña, Los Amigos de Durruti, los trotsquistas y los sucesos de mayo, Madrid, Campo Abierto, 1978.

G. Munis [Manuel Martínez], Jalones de derrota promesa de victoria. Critica y teoría de la revolución española, 1930-1939. Obras completas, Tomo IV, Brenes, Muñoz Moya Editores Extremeños, 2003.

Leon Trotski. A Revolução Espanhola - compilação, São Paulo, Iskra, 2014.

, “A traição do 'Partido Operário da Unificação Marxista' espanhol” [1936], in , A Revolução Espanhola, op. cit., p. 158-60.

, "Classe, partido e direção. Por que o proletariado espanhol foi derrotado? Questões de teoria marxista" [1940], in . A Revolução Espanhola, op. cit., p. 267-277.

, "Lições da Espanha: última advertência" [1937], in A Revolução Espanhola, op. cit., p. 244-259.

${ }^{32}$ Ibid., p. 12.

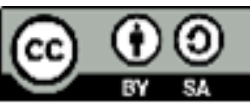


Leon Trotsky, O programa de transição para a revolução socialista [1938], São Paulo, Sundermann, 2008.

Luis González, El trotskismo en España. Las organizaciones trotskistas en el Estado español desde 1930 a la actualidad, Madrid, POSI, 2006.

M. Casanova [Mieczyslaw Bortenstein], El Frente Popular abrió las puertas a Franco [1939], disponível em http://www.marxistsfr.org/espanol/bortenstein/1939/frente/index.htm, acessado em dezembro de 2016.

M. Casanova [Mieczyslaw Bortenstein], Espanha abandonada. Como Stalin abriu as portas a Franco [1939], Lisboa, Antídoto, 1977.

Pelai Pagès, El movimiento trotskista en España, 1930-1935: La izquierda comunista de España y las disidencias comunistas durante la Segunda República, Barcelona, Península, 1977.

Pierre Broué, "Trotski e a guerra civil espanhola" [1975], in Leon Trotski, A Revolução Espanhola - compilação, São Paulo, Iskra, 2014, p. 339-58.

Pierre Broué, "Trotsky y la guerra civil en España" [1975], in La revolución española, vol. 2, Barcelona, Fontanella, 1977, disponível em https://www.marxists.org/espanol/broue/1975/trotsky_y_la_guerra_civil_en_esp.htm, acessado em dezembro de 2016.

Robert J. Alexander, International Trotskyism, 1929-1985: a documented analysis of the movement, Durham, Duke University Press, 1991.

Sam Borstein e Al Richardson, The War and the International: A History of the British Trotskyist Movement, 1937-1949, London, Socialist Platform, 1986.

\section{Digitais / online}

Andy Durgan, "The Spanish Trotskyists and the Foundation of the POUM", Revolutionary History, 4:1-2, versão digital, [s.p.], disponível em https://www.marxists.org/history/etol/document/poum/index.htm, acessado em junho de 2016.

Felix Morrow, Revolution and Counter Revolution in Spain [1938], London, New Park Publications, 1963, disponível em https://www.marxists.org/archive/morrow-felix/1938/revolutionspain/, acessado em junho de 2016.

Leon Trotsky, "Two Articles on Centrism", Class Struggle, 4:8, agosto de 1934, versão digital, [s.p.], disponível em https://www.marxists.org/archive/trotsky/1934/02/centrism.htm, acessado em junho de 2016.

Marcio Lauria Monteiro, "O movimento trotskista internacional e as revoluções do pós-guerra", Outubro 27, novembro de 2016, disponível em http://outubrorevista.com.br/o-movimentotrotskista-internacional-e-as-revolucoes-do-pos-guerra/, acessado em dezembro de 2016.

Victor Alba \& Stephen Schwartz, Spanish Marxism versus Soviet Communism. A History of the P.O.U.M. in the Spanish Civil War [1988], New Bunswick and London, Transaction Publishers, 2009, edição digital de 2016, disponível em https://libcom.org/library/spanish-marxism-vs-sovietcommunism-history-poum-spanish-civil-war-victor-alba, acessado em junho de 2016.

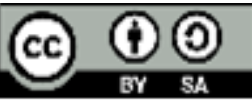

